\title{
COLONIZAÇÃO, CULTURA E LÍNGUA EM CAMPOS DOS GOYTACAZES: A QUESTÃO AFRICANA NA CONSTRUÇÃO IDENTITÁRIA DO MUNICÍPIO ${ }^{1}$
}

\section{COLONIZATION, CULTURE AND LANGUAGE IN CAMPOS DOS GOYTACAZES: THE AFRICAN QUESTION IN THE IDENTITY CONSTRUCTION OF THE MUNICIPAL}

\author{
Neilda da Cunha Alves Ferro ${ }^{2}$ \\ Thiago Soares de Oliveira ${ }^{3}$
}

Resumo: A partir da discussão sobre a presença negra no processo de construção da identidade de Campos dos Goytacazes, enfatizando o rotacismo como herança fonéticofonológica africana presente no falar dos nativos de tal região, objetiva-se verificar a relação existente entre o rotacismo, elemento fonético-fonológico de origem africana, segundo Aragão (2010/2011), a colonização e a influência histórica dos negros escravizados nestas terras. Para tanto, este trabalho teórico ampara-se metodologicamente na pesquisa bibliográfica e justifica-se com base em disposições expressas nas Diretrizes Curriculares Nacionais para a Educação das Relações Étnico-Raciais e para o Ensino de História e Cultura Afro-Brasileira e Africana.

Palavras-chave: Africanidades; Construção identitária; Campos dos Goytacazes; Rotacismo.

Abstract: From the discussion of the black presence in the process of constructing the identity of Campos dos Goytacazes, emphasizing the rotacism as the African phoneticphonological inheritance present in the native speakers of this region, the objective is to verify the relation between the rotacism, phonetic element according to Aragão (2010/2011), the colonization and historical influence of blacks enslaved in these lands. To this end, this theoretical work is methodologically supported by bibliographic research and is justified on the basis of provisions expressed in the National Curricular Guidelines for the Education of

\footnotetext{
${ }^{1}$ Este artigo é parte do resultado de pesquisa desenvolvida no âmbito do Instituto Federal Fluminense.

${ }^{2}$ Especialista em Políticas Públicas pela Universidade Federal do Rio de Janeiro (UNIRIO). Graduada em Serviço Social pela Universidade Federal Fluminense (UFF) e licenciada em Letras (Português e Literaturas) pelo Instituto Federal de Educação, Ciência e Tecnologia Fluminense. Atua como Assistente Social na Secretaria Municipal de Direitos Humanos e Social de Campos dos Goytacazes/RJ, bem como na Secretaria Municipal de Assistência Social e Direitos Humanos de São João da Barra/ RJ. Tem interesse nas áreas de Linguística e Questões Sociais e Raciais. E-mail: neildasocial@yahoo.com.br

${ }^{3}$ Doutor em Cognição e Linguagem pela Universidade Estadual do Norte Fluminense Darcy Ribeiro (UENF). Atualmente é Professor da Licenciatura em Letras (Português e Literaturas), da Especialização em Literatura, Memória Cultural e Sociedade e do Programa de Pós-Graduação Strito Sensu em Educação Profissional e Tecnológica (ProfEPT) do Instituto Federal Fluminense (IFF). É pesquisador vinculado ao Núcleo de Estudos Culturais, Estéticos e Linguagens do IFF, na linha de História da Língua Portuguesa, e coordenou por dois anos a pesquisa intitulada "O Português Histórico e a sua aplicabilidade na explicação de fenômenos fonéticos da Língua Portuguesa". Coordena, desde 2018, a pesquisa "Descrição e explicação de fenômenos fonéticos sob o viés da Linguística Histórica”. Tem experiência em Letras, com ênfase nas seguintes áreas: Tradição Gramatical da Língua Portuguesa, Estudos Formais de Língua Latina e de Gramática Histórica, Linguística Clássica e História da Língua Portuguesa. E-mail: so.thiago@hotmail.com
} 
Ethnic-Racial Relations and for the Teaching of Afro-Brazilian and African History and Culture.

Keywords: Africanities; Identity construction; Campos dos Goytacazes; Rotacism.

\section{Considerações iniciais}

A relação entre a colonização, a cultura africana e traços do linguajar do povo brasileiro tem despertado o interesse de estudiosos como Pessoa de Castro (2001), Lucchesi (2012), Lifschitz (2008), Lima (1981), ou seja, pesquisadores de vários campos de conhecimento, tendo em vista a formação mista da identidade étnica, linguística e cultural do Brasil.

Com efeito, vários elementos africanos colaboraram para a composição das características que tornam o Brasil peculiar, se comparado a algumas outras ex-colônias portuguesas, devido ao contato e à influência de línguas africanas neste território. Em Campos dos Goytacazes, um traço fonético desponta como um resultado da "amálgama" que aconteceu nesta cidade: trata-se do rotacismo, um fenômeno linguístico que diferencia a forma de fala de determinado grupo, por causa de fatores relacionados a aspectos externos (como é o caso do contato linguístico) e a internos, inerentes ao nível fonético-fonológico, causando a troca do /1/ pelo /r/ na oralidade. Pontua-se que esse fenômeno é antigo na região de Campos, mas não é exclusividade do falar local, ou seja, pertence a fala popular do Brasil e, por isso, é também observado em outras regiões.

Com o objetivo de verificar a ligação existente entre o rotacismo como elemento fonético-fonológico de origem africana e os processos de colonização e influência histórica dos negros escravizados nestas terras, este trabalho teórico, amparado metodologicamente na pesquisa bibliográfica, embasa-se precipuamente nas obras de Oscar (1985), Lucchesi et al. (2009), Lamego Filho (1945), Pessoa de Castro (1978; 1984; 2011), Aragão (2010/2011), entre outros. Além disso, busca-se respaldo nas Diretrizes Curriculares Nacionais para a Educação das Relações Étnico-Raciais e para o Ensino de História e Cultura Afro-Brasileira e Africana, de 2004, que alterou os artigos 26 e 79 da Lei de Diretrizes e Bases da Educação Nacional (LDBEN - Lei 9394/96), em razão da inclusão obrigatória da temática da história da cultura africana e afro-brasileira no sistema educacional do país, como propunha a lei 10639/03. De modo geral, as orientações estabelecidas nas Diretrizes Curriculares propiciam um diálogo entre os sistemas de ensino, a comunidade escolar e os educadores quanto 
Às relações étnico-raciais, ao conhecimento e valorização da história e cultura dos afro-brasileiros, à diversidade da nação brasileira, ao igual direito à educação de qualidade, isto é, não apenas direito ao estudo, mas também à formação para a cidadania responsável pela construção de uma sociedade justa e democrática (BRASIL, 2004, p. 10).

Assim, tais orientações interferem no processo de ensino e de aprendizagem demandando a qualificação de professores de diferentes áreas do conhecimento, pois

\begin{abstract}
A educação constitui-se um dos principais ativos e mecanismos de transformação de um povo e é papel da escola, de forma democrática e comprometida com a promoção do ser humano na sua integridade, estimular a formação de valores, hábitos e comportamentos que respeitem as diferenças e as características próprias de grupos e minorias (BRASIL, 2004, p. 07).
\end{abstract}

Desse modo, considera-se relevante o estudo da composição histórica da sociedade campista, cuja marca (uma delas) também está na ocorrência do rotacismo na fala, o que contribui para a formação de uma identidade desse povo, incluído em uma sociedade multicultural e pluriétnica, assim como o território nacional. Na verdade, os dados oficiais do censo realizado pelo Instituto Brasileiro de Geografia e Estatística (IBGE), no ano de 2010, informam que a cidade de Campos dos Goytacazes, que está localizada na região Norte do Estado do Rio de Janeiro, tem 463.731 habitantes. Segundo o aludido censo, 235.297 pessoas são da cor negra, ou seja, o município tem pessoas pretas e pardas ${ }^{4}$ como mais de $50 \%$ dos habitantes. Baseado nesses dados, o Centro de Informações e Dados de Campos (CIDAC) distribui esses habitantes entre distritos e bairros.

Portanto, com o trabalho, busca-se mostrar um ponto de influência dos africanos escravizados na cidade de Campos dos Goytacazes, já que esses indivíduos tiveram de se adaptar à língua portuguesa por necessidade de sobrevivência e para facilitar a comunicação. Espera-se fomentar ideias que possibilitem uma maior busca por conhecimentos relacionados

\footnotetext{
${ }^{4}$ Para efeito de esclarecimento, reporta-se ao art. $1^{\circ}$ do Estatuto da Igualdade Racial, instituído pela Lei 12.288, de 20 de julho de 2010 que, no parágrafo único, inciso IV, considera que a população negra como o "conjunto de pessoas que se autodeclaram pretas e pardas, conforme o requisito cor ou raça usado pela Fundação Instituto Brasileiro de Geografia e Estatística (IBGE), ou que adotam autodefinição análoga".
} 
à influência africana no falar do povo campista e, desse modo, contribuir para a valorização da cultura africana neste município.

\section{Da colonização e do hibridismo de povos: a questão escravista e a formação sociocultural}

Situada à margem direita e esquerda do rio Paraíba do Sul, a cidade de Campos dos Goytacazes tem uma extensão de 4.026,696 km², sendo um dos primeiros zoneamentos estabelecidos na província fluminense. Entre os 92 municípios do Estado do Rio de Janeiro contemporâneo, trata-se do maior em área. Localizado na região norte fluminense, o território, de acordo com os dados do último censo demográfico do Instituto Brasileiro de Geografia e Estatística (IBGE) realizado no ano de 2010, é habitado por uma população que totaliza, atualmente, 463.731 pessoas $^{5}$.

Segundo as informações de Lamego Filho (1945), o processo de colonização da região campista inicia-se na primeira metade do século XVII com a pecuária constituída em pequenas propriedades que os colonizadores portugueses levaram para a baixada campista. Possivelmente na região de Campo Limpo, ao norte da Lagoa Feia, surgiram as primeiras cabeças de gado e a construção dos primeiros currais.

\footnotetext{
A emblemática Baixada Campista apresenta uma grande importância histórica para o município, pois foi por ela que se iniciou a colonização portuguesa (1525). Em 1539, a região foi obtida por Pero Góis e Gil de Góis, porém foi logo desprezada por causa das contendas com os nativos, que lutaram por suas terras (SILVA e SILVA, 2016, p. 45).
}

O colono estabilizou-se nas fazendolas e o seu mundo estava na zona rural: a moradia, a família, o engenho, o rebanho, os escravos e os canaviais. Assim, pouco se dirigia à vila. Para Pessoa de Castro (1978), era o isolamento que promovia a propagação de transferências culturais mútuas, que convergiam para a conservação da tradição dos povos envolvidos no ambiente familiar ou no trabalho. Logo depois, a cultura canavieira desemboca na região, transformando-se, no século XVIII, na principal economia da província.

\footnotetext{
${ }^{5}$ Fonte: IBGE - Censo Demográfico 2010.
} 
Tendo sido elevada à categoria de cidade no século $\mathrm{XIX}^{6}$, no período imperial do país, Campos foi considerado um dos mais importantes polos econômicos e sociais do Brasil, devido à sua relevante produção açucareira, que alavancou o progresso, especialmente nos séculos XVIII e XIX.

O campista mantém verdadeiro cordão umbilical com a economia voltada para a produção de açúcar. Nos dias atuais podemos considerar que Campos é a única cidade brasileira que cresceu, progrediu, tornou-se populosa e prosperou exclusivamente à custa da atividade açucareira (PINTO, 2006, p. 91).

Como se observa, o açúcar marcou o desenvolvimento social e econômico campista, garantindo o escoamento da produção para mercados como o Rio de Janeiro e influenciando a fixação do campista na terra, tendo como meio de produção o sistema escravista, implantando uma estrutura social identificada pela relação entre os proprietários de engenhos e a massa trabalhadora escrava. Nesse sentido, o desenvolvimento econômico do município foi conduzido pela força de trabalho escrava, principalmente nos séculos XVIII e XIX. Soares (2010) relata que, conforme a atividade açucareira expandia-se, demandava mais mão de obra barata e, por isso, nas primeiras décadas do século XIX, os produtores campistas intensificaram a aquisição de escravos africanos adultos nos portos da província fluminense.

O auge do século XVIII tornou a cana-de-açúcar a principal atividade econômica da região, em substituição ao gado. Oscar (1985) observa que, em 1785, Campos possuía 236 engenhos, 9 engenhocas e 218 currais, tudo sustentado pelos braços de 12.085 escravos, que produziam açúcar e aguardente, cuidavam dos bovinos e dos cavalos e de outros produtos agrícolas. A produção açucareira que desenvolveu econômica e socialmente o norte fluminense era manipulada, inicialmente, nas engenhocas construídas pelas médias e pequenas propriedades, sendo que quatro delas se destacaram por serem as primeiras a implantar tal atividade: a fazenda do Morgado (herdeiros de Miguel Ayres Maldonado, um dos Sete Capitães); a fazenda São Bento, dos padres beneditinos; a fazenda do Visconde de Asseca (descendente de Salvador Correia de Sá) e a fazenda do Colégio, dos padres Jesuítas.

\footnotetext{
${ }^{6}$ Em 1677, o Visconde d'Asseca funda a vila de São Salvador de Campos dos Goytacazes e, em 28 de março de 1835, a vila foi elevada à categoria de cidade.
} 
Segundo Pinto (2006, p. 28), essa emergência no processo produtivo fez com que a população campista constituísse um hibridismo de povos, instituindo a mescla de brancos, negros e mestiços "que convivem numa sociedade de grandes contrastes culturais", com destaque para o grande contingente de população escrava africana. No livro Na Taba dos Goytacazes, o jornalista e pesquisador Oliveira (1988) faz uma análise da concepção cultural e social de Campos, dizendo que basicamente a formação racial campista concentrou-se na relação entre o colono português e os africanos escravizados, pois nenhum esforço foi realizado para que os colonos estrangeiros fixassem moradia nos Campos.

\begin{abstract}
Porque em Campos nunca vingou a colonização que não fosse a portuguesa. Para aqui vieram muitos ingleses e franceses como engenheiros mecânicos e toda a parafernália das oficinas dos engenhos e depois usinas de açúcar. Não houve miscigenação em Campos. Apenas o português e o preto formaram a nossa etnia. Houve tentativa, inclusive instalou-se uma colônia de belgas na Pedra Lisa, mas em pouco eles abandonaram, não se sabe por conta do clima ou de outro fator (OLIVEIRA, 1988, p. 57).
\end{abstract}

Ainda de acordo com Oliveira (1988), essa instalação da colônia belga na região da Pedra Lisa, localizada no norte do município, ocorreu no ano de 1844 , período de pleno desenvolvimento da região devido ao processo de industrialização ocorrido por causa da instalação de maquinários modernos nas usinas de cana-de-açúcar. Nesse sentido, pelas análises do pesquisador, confirma-se que a interação entre o escravo africano e o colonizador português foi importante para a composição da identidade e da sociedade campista, uma vez que outros povos não prosperaram e não se fixaram no solo da planície naquele momento.

Assim, foi no bojo dessa relação antagônica entre o escravo e o senhor que se desenhou a concepção sociocultural da cidade de Campos dos Goytacazes, podendo-se dizer que o primeiro estava subordinado ao seu proprietário, sem domínio de seu corpo ou de seu valor, sem garantia de direitos, já que, além de ter explorada a sua força de trabalho, não tinha liberdade religiosa, de lazer ou autonomia para desenvolver atividades não autorizadas, nem mesmo de ofertar aos seus familiares condições melhores de sobrevivência, visto que toda a sua vida era submetida à vontade e à autonomia do seu senhor.

No ano de 1556 a região apresentava grande progresso, a agricultura desenvolvia-se ao impulso do trabalho dos escravos, os engenhos começavam a moer, produzindo açúcar, fabricando aguardente. A população se desenvolvia, aumentando o número de casas de palha que se situavam às margens do Paraíba (PEIXOTO, 1969, p. 43). 
Acrescenta Peixoto (1969) que esse povoamento culminou com a prosperidade produtiva da região, no século XVIII, reforçada pela penetração de colonos portugueses vindos principalmente de Minas Gerais e de São Paulo, rumo ao norte fluminense. Assim, a influência dos colonos possibilitou a formação da aristocracia rural fluminense, que, no século XIX, aumenta a dependência da mão de obra dos africanos escravizados, os quais se tornaram importantes construtores do progresso da região, assim como em todo o país, já que participavam de todas as atividades agrícolas, pecuária, mineração e até mesmo do serviço doméstico. Note-se que sem nenhuma remuneração.

Nessa linha de raciocínio, "o branco veio se juntar ao negro trazido como escravo das costas Africanas e da junção das duas raças foram surgindo os tipos como hoje conhecemos: mulatos claros e mulatos escuros" (PINTO, 2006, p. 31). Nesse ponto, concorda-se com Pinto (2006) quando este resume a população de Campos à combinação entre brancos, negros e mestiços. À matriz étnica que compôs a sociedade campista foi incorporada uma gama de tradições, costumes e valores que cada povo trouxe da sua origem e, possivelmente, tais elementos serviram de subsídios para a composição das características próprias que identifica um campista.

Assim a sociedade campista organizou-se, constituindo a identidade sociocultural de uma população composta por grupos étnicos que traziam suas heranças culturais. Oscar (1985, p. 149) descreve a presença dos grupos étnicos na planície como "um verdadeiro caldeirão racial", pois, do princípio da colonização ao fim do comércio negreiro, vieram para Campos muitos povos de etnias, valores, costumes e linguajares diversificados, sobretudo os africanos cujas tradições eram "abafadas" pelas suas condições de cativos. Prova disso é que até os seus nomes eram escolhidos por seus donos ${ }^{7}$. Assim,

\footnotetext{
${ }^{7}$ Sobre essa questão Oscar (1985, p. 150) utiliza os seguintes trechos de notícias do Jornal Monitor Campista: "Fugiu a Sebastião Gomes de Souza Cruz um escravo de nome Joaquim, de nação Congo, boa estatura; quem o prender e levar ao seu senhor no Queimado será bem gratificado" ou "Fugiu a João Pinto Lopes, de sua fazenda de São Fidélis, denominada S. João, um escravo de nome Ricardo, de nação Camundongo", seguidos do nome da tribo africana de sua origem. Quando brasileiro nativo, o nome dado pelo seu dono deveria ser seguido da denominação "crioulo"”.
} 
Analisando as relações cotidianas entre senhores e escravos nos Campos dos Goytacazes, pudemos perceber que os critérios e definições do que era ou não justo ou excessivo, cruel ou benevolente estavam assentados na dinâmica destas relações no cotidiano de resistências e acomodações, confrontos e solidariedade que aqueles homens e mulheres mantinham entre si (LARA, 1988, p. 342).

Percebe-se que, para além da relação entre senhores e escravos, essas unidades nucleares construíram culturas distintas de sua origem e tiveram dificuldade em manter suas tradições por causa da hegemonia branca. Assim, pela imposição, os cativos absorveram a cultura de seus senhores como a crença, alimentação, vestuário, linguagem, mas, de forma camuflada, procuraram valorizar as suas práticas habituais.

\begin{abstract}
Os africanos que para cá vieram transferidos não trouxeram apenas a sua força de trabalho, mas também transportaram suas culturas, das quais as línguas são uma expressão importante, embora pouco considerada nos estudos que investigam a contribuição ou a participação dos africanos escravizados na constituição da nacionalidade brasileira (CUNHA e PETTER, 2015, p. 221).
\end{abstract}

Nesse sentido, os povos africanos marcaram a formação da nação brasileira, influenciando e sendo influenciados, por conseguinte, na constituição da identidade nacional, inclusive na língua. O fato é que, no Brasil, país em que se inclui o município de Campos dos Goytacazes, a identidade é resultado de uma mescla, já não se trata mais da cultura lusitana e da africana consideradas separadamente, mas de um produto da influência mútua entre ambas. Entende-se, nessa linha de raciocínio, que a riqueza cultural e linguística que se manifesta no português brasileiro deve muito à influência africana.

Além da posse dos escravos, o patrimônio dos latifundiários campistas contava com heranças e propriedades nas zonas rural e urbana e, ainda hoje, é possível encontrar casarões como o Solar dos Airizes (localizado na BR 356 ${ }^{8}$ ); o Solar do Barão da Lagoa Dourada (atualmente Colégio Liceu de Humanidades de Campos, adquirido pela Câmara, no século XIX) e outros que serviram de cenário para histórias marcadas pelo sofrimento e exploração dos escravizados. Ao mesmo tempo, era nesses espaços que os cativos descobriam a ajuda mútua e as formas de convívio social, reconhecidas pela manifestação de rituais e valores de suas origens, por meio da dança, do batuque, da comida, da linguagem e da religiosidade. Em

\footnotetext{
${ }^{8}$ Segundo Pinto (2006), em 1847, D. Pedro II hospedou-se nesse casarão numa de suas viagens a Campos.
} 
meio a um cotidiano de crueldade e submissão, os africanos escravizados aproveitavam os ambientes coletivos, como o local de trabalho e as senzalas, para articular símbolos como forma de comunicação, mesmo diante de uma variedade de grupos étnicos de nações africanas. Assim, quando eles eram acomodados estrategicamente pelos seus proprietários de forma a evitar as rebeliões e motins, a comunicação "fluía".

Tais manifestações caracterizavam-se como tática de interação, preservação e resistência cultural, fatores determinantes à continuidade cultural e costumeira da origem desses indivíduos, apesar de suas identidades distintas, que resultaram num hibridismo sociocultural e linguístico dos povos escravizados em Campos. Por outro lado, Lima (1981) discorre sobre a "proximidade íntima" que os escravos e os latifundiários estabeleceram no cotidiano do sistema escravista. Trata-se do ajustamento na relação entre senhor e escravo, analisado pela autora a partir de dois níveis: num primeiro momento, refere-se à relação de pessoa para coisa, porque o escravo é um organismo produtivo que tem a sua força de trabalho dominada e aparelhada para produzir, de sol a sol, o máximo possível e, nesse caso, é objeto de uma relação predominantemente econômica, limitada entre os canaviais e a senzala; num segundo momento, contudo, a autora menciona uma relação patriarcal mais intimista e desenvolvida no contexto doméstico, pois, alguns escravos conviveram na casa grande desempenhando as funções de ama de leite, pajem, mucamas.

Em suma, independentemente do local onde ocorria o contato entre dominantes e dominado (casa grande ou senzala), percebe-se que as duas relações se gestavam no sistema escravista caracterizado pela presença do autoritarismo, do "tronco", da repreensão, da violência, do trabalho forçado, do controle e da limitação das ações dos cativos.

Com efeito, muitos escravizados mantinham relações sociais mais próximas com os seus senhores, especialmente aqueles que desempenhavam atividades diárias nos casarões (chamados de escravos domésticos). Além disso, antes de chegarem ao Brasil, os africanos desenvolveram uma relação com os portugueses devido à colonização praticada por Portugal na África anos antes de chegar à América, facilitando-lhes o conhecimento da cultura e dos valores da metrópole, sobretudo no que diz respeito à língua e à religião. Nesse sentido, Lucchesi et al. (2009) comentam que a maioria dos escravos tinha dificuldades de assimilação da língua portuguesa porque executavam as suas funções nos canaviais, ao contrário daqueles cativos que desempenhavam serviços domésticos e urbanos, cuja absorção linguística era 
facilitada porque estes "provavelmente tinham um maior acesso aos modelos da língua-alvo e adquiriram uma variedade de português mais próximo da língua de seus senhores" (LUCCHESI et al., 2009, p. 67).

Para Oscar (1985) a formação sociocultural e econômica de Campos ocorre em duas fases confrontando senhores/fazendeiros e escravos. Enquanto a primeira fase iniciou-se na colonização, indo até a mecanização dos engenhos, o que já foi explicitado anteriormente por meio de outros autores, a segunda foi da criação dos engenhos centrais à abolição da escravatura. Nesta, iniciada com o capitalismo pré-industrial, devido ao aumento da produção açucareira, de forma mecanizada, exigia-se cada vez mais o trabalho braçal para dar conta das demandas exportadoras, sobretudo com a vinda da família real, em 1808, para o Rio de Janeiro, local que se tornou um dos grandes importadores da produção açucareira campista. Essa fase estende-se até o período abolicionista, quando o africano cativo impulsiona a resistência à escravidão e, por meio de ações coletivas e com o apoio dos abolicionistas, promovem um embate entre escravocratas e antiescravistas.

Sobre a especificidade da composição populacional campista, é preciso observar que

A análise dos registros de batismo revela que, nas três primeiras décadas do século XIX, os cativos recém-chegados identificados pelos padres como angolas constituíam 91\% dos adultos com sacramento ministrado em São Salvador. Logo, os registros paroquiais não deixam a menor dúvida: a maior parte dos africanos, cuja origem não foi especificada nos inventários, era composta pelos pretos de nação Angola (SOARES, 2010, p. 77).

Nesses termos, emerge a ideia de que o contato entre essas categorias provavelmente marca a configuração sócio-histórica do município, levando-se em conta que a presença do africano escravizado conferiu uma nova identidade étnica e cultural no seio da sociedade em questão, já que, conforme se sabe, além da sua força de trabalho, o africano trouxe na sua bagagem elementos como os valores da sua terra, crenças, tradições, etc. Dentre esses elementos, podem ser destacados aspectos linguísticos africanos que, ao que parece, influenciaram o falar do povo campista determinando um papel importante na difusão da língua portuguesa no Brasil.

Os escravos vindos da África tiveram que aprender o português como segunda língua em condições bem diversas, no ambiente do trabalho forçado da lavoura e das 
minas. Já que os que nasciam no Brasil, em muitos casos, eram filhos de pais que falavam línguas africanas diferentes e mutuamente ininteligíveis, adquiriam o português como língua materna a partir do modelo imperfeito do português falado como segunda língua pelos adultos (LUCCHESI et al., 2009, p. 75).

Como se nota, o escravismo colocou um grande número de indivíduos numa variedade linguística devido aos falares diferentes e ininteligíveis, fazendo-se necessária a adoção de uma linguagem comum e emergente para facilitar a comunicação entre os sujeitos, o que desencadeou um aprendizado mais "simplificado" da língua materna. Ocorre que o fluxo de negros enviados para o Brasil, pelos portugueses, obrigou os escravos a adaptarem a língua portuguesa como instrumento de sobrevivência, uma vez que o navio trazia cativos de diversas regiões da África, compostas de pluralismo linguístico, dificultando, pois, a comunicação. Ressaltamos que, no século XIX, Campos era diferente da maior parte do Brasil, pois continha um conjunto relativamente homogêneo de africanos oriundos da região de Angola, conforme destacado por Soares (2010). Pessoa de Castro (1978, p. 14) pondera essa questão relatando que, "nas senzalas, a necessidade de comunicação entre os povos lingüisticamente diferenciados deve ter provocado a emergência de uma espécie de língua franca ou dialeto das senzalas". A autora considera a possibilidade de que esses grupos linguísticos possam ter sido atraídos "pela língua do grupo etnicamente majoritário ou de maior prestígio social" (PESSOA DE CASTRO, 1978, p. 15).

Para Lucchesi (2012), a cultura predominante é a africana, particularmente pela servidão da sua força de trabalho, por mais de 300 anos. Além disso, o pesquisador aponta que a propagação da língua portuguesa no Brasil contou com a vinda dos quatro milhões de povos africanos escravizados "e que foram forçados a abandonar as suas línguas nativas e adotar o português como língua de comunicação.” (LUCCHESI, 2012, p. 46). Nesse sentido, pode-se dizer que, no município de Campos dos Goytacazes, a existência de particularidades na manifestação e no manejo da língua talvez seja resultado de influência africana, o que se pôde perceber pela leitura dos diversos autores a quem se recorreu para a confecção deste trabalho. No histórico linguístico deste município, há a ocorrência do denominado rotacismo, que será abordado no próximo item. 


\section{Da língua e da identidade: o rotacismo como parte da configuração linguística dos nativos campistas}

Parte do desenvolvimento sociocultural de Campos dos Goytacazes foi, como se relatou anteriormente, resultado dos traços culturais do colonizador português em contato com o cotidiano dos africanos escravizados, os quais foram trazidos para o município a partir da necessidade de mão de obra propícia ao cultivo da cana-de-açúcar. Ao analisar especificamente a questão do rotacismo, este trabalho considera a questão relativa às africanidades, segundo a qual o uso da língua é passível de variações fonéticas, morfológicas, sintáticas e lexicais de acordo com a condição sociocultural do falante (BAGNO, 1997).

Atualmente, em Campos dos Goytacazes, a maioria dos bairros periféricos é habitada por um número significativo ${ }^{9}$ de pessoas de etnia negra ${ }^{10}$, distribuídas entre os bairros e distritos da cidade, sendo esta a segunda cidade brasileira com maior massa populacional de negros, ficando atrás apenas de Salvador-BA. Mais de 50\% dessa população declara-se negra (pretas e pardas), conforme se nota pela análise da Tabela 1:

\begin{tabular}{|c|c|c|c|c|c|}
\hline \multirow[b]{2}{*}{ COR OU RAÇA } & \multirow{2}{*}{ TOTAL } & \multicolumn{4}{|l|}{ SEXO } \\
\hline & & HOMENS & $\%$ & MULHERES & $\%$ \\
\hline Branca & 225088 & 105588 & 22,77 & 119500 & 25,77 \\
\hline Preta & 65517 & 32667 & 7,04 & 32850 & 7,08 \\
\hline Amarela & 2985 & 1374 & 0,3 & 1611 & 0,35 \\
\hline Parda & 169777 & 83458 & 18 & 86319 & 18,61 \\
\hline Indígena & 302 & 142 & 0,03 & 160 & 0,03 \\
\hline Sem declaração & 62 & 30 & 0,01 & 32 & 0,01 \\
\hline TOTAL & 463731 & 223259 & 48,14 & 240472 & 51,86 \\
\hline
\end{tabular}

\footnotetext{
${ }^{9}$ O número mencionado poderá ser consultado no site do Centro de Dados de Campos (CIDAC).

${ }^{10}$ População negra é o "conjunto de pessoas que se autodeclaram pretas e pardas, conforme o quesito cor ou raça do IBGE, ou que adotam definição análoga" (BRASIL, lei 12.288/2010).
} 
Tabela 1: Dados do universo cor/raça

Fonte: IBGE - Censo Demográfico 2010

Elaboração: Centro de Informações e Dados de Campos - CIDAC/PMCG

Diante desses dados e dos relatos anteriores, percebe-se que, desde a colonização, os africanos sempre estiveram em número populacional bem expressivo em todo o território nacional. A Tabela 1 mostra que a população negra de Campos (soma entre pretas e pardas) totaliza mais de $50 \%$. Por meio dos negros e seus descendentes, pode-se dizer, então, que o português brasileiro foi influenciado no território campista. $\mathrm{Na}$ verdade, a presença maciça do africano na cidade pode ser notada (até mesmo por observação pessoal), sendo plausível supor uma influência também nas manifestações socioculturais dos colonizadores portugueses. A fonética africana é um exemplo disso porque, em algumas regiões, os dialetos africanos interferiram na construção da linguagem popular brasileira (MENDONÇA, 1935). Eis alguns exemplos de fenômenos de influência fonética destacados por Mendonça (1935):

- Vocalização: o fonema linguopalatal lh é transformado na semivogal y, com em Mulher > Muyé;

- Assimilação: o fonema j dá lugar à sibilante $\mathrm{z}$ e o g, transformando-se em z antes de e e i, como ocorre em Jesus > Zezús; José> Zozé; Genebra > Zinébra; Registro > Rezisto;

- Dissimilação: ocorre em grupos consonânticos de difícil elocução, a exemplo de Negro > Nego; Alegre> Alegue;

- Aférese: a queda do(s) fonema(s) inicial (is), como em Estar > Tá; Você > Ocê; Acabar > Cabá; Sebastião > Bastião;

- Apócope: a queda ocorre em 1 e r finais, como General > Generá; Cafezal > Cafezá; Mel > Mé; Esquecer > Esquecê; Artur >Artú.

- Subarácti: eliminação de encontros consonantais, como em Cláudio > Culáudio; 
- Rotacismo: substituição do r pelo 1 palatal ou o abrandamento em $\mathrm{r}$ fraco (ocorreu devido à inexistência do $\mathrm{r}$ nas línguas bantu). Alguns exemplos: Rapaz > Lapassi; Carro > calo.

Em relação ao rotacismo campista, entende-se tratar-se de um fenômeno que é herança africana, cuja manutenção se deu não só em razão do quantitativo de negros no município, mas também por "propagação fonética" passada em família, o que pode ser verificado, por analogia, no livro A língua de Eulália, de Bagno (1997). Em tal obra, a personagem Irene explica que a variação se estabelece por meio de aspectos presentes no uso da fala, caracterizando o linguajar nas esferas da língua padrão ou não padrão. A língua padrão é aquela normativa, ensinada na escola e que supostamente acarreta prestígio social à minoria dos falantes porque dispõe de um "arcabouço cultural" elitizado, fazendo com que esses falantes se comuniquem com supostas habilidades e eficácias. À língua padrão, na verdade, poucos brasileiros têm acesso. A despeito do entendimento de Bagno (1997), que bem representa a língua em seu aspecto variacional, trata-se, aqui, a questão do rotacismo a partir de um viés histórico que, em princípio, não recorre a conceitos específicos da ciência linguística, mas da Sociolinguística ${ }^{11}$, pois considera a influência africana como possibilidade histórico-explicativa para a ocorrência de rotacismos na cidade de Campos dos Goytacazes.

De acordo com Bechara (2009, p. 52), “a gramática normativa recomenda como se deve falar e escrever segundo o uso e a autoridade dos escritores corretos e dos gramáticos e dicionaristas esclarecidos". Portanto, o indivíduo que se desvia do padrão ideal de uso da língua pode ser classificado como inculto e incompetente, ainda que se tenha claro que as modalidades escrita e falada são distintas entre si. Nesse sentido, a língua pode se apresentar como um elemento excludente e marginalizador, se considerado que a norma-padrão é a natural, a espontânea, o que de fato não o é. É da fala cotidiana das pessoas que resultam as alterações na "língua portuguesa brasileira"; a norma pode ou não registrar tais fatos de língua. Nessa perspectiva, para Bagno (2013), os fenômenos da língua têm uma explicação histórica, linguística e social, estando sujeitos a mudanças, já que a língua faz parte de um

\footnotetext{
${ }^{11}$ Para efeitos deste trabalho, a Socioliguística é considerada um ramo específico da Linguística.
} 
contexto, devendo, por isso, ser considerada dentro de uma conjuntura sociocultural. Deste ponto, parte a argumentação aqui construída.

A rigor, pelo viés linguístico, a concepção da identidade de um povo permite a interação social dos atores, pois, segundo Brandão (2012) ${ }^{12}$, a linguagem se funda num discurso engajado à realidade dos falantes como um modo de produção social porque ajusta as relações interindividuais. Portanto, a língua é "lugar de conflito, de confronto ideológico, não podendo ser estudada fora da sociedade, uma vez que os processos que a constituem são histórico-sociais" (BRANDÃO, 2012, p. 11), ou seja, como instrumento de comunicação, só tem valor vinculado ao contexto de uso. Por isso, a língua é variável e constituída de fenômenos que a especificam de acordo com o seu uso.

\begin{abstract}
No caso específico do português trazido para o Brasil, é sempre bom lembrar que não foram os doutores de Coimbra nem os poetas da corte de Lisboa que colonizaram o nosso território. Para cá vieram os marinheiros, mercadores, baixos funcionários, pequenos artesãos, além de degredados políticos e religiosos, uma população essencialmente masculina e muito pouco letrada. Vinham das mais diversas regiões de Portugal, ou seja, falavam diferentes variedades do português europeu medieval (BAGNO, 2013, p. 27).
\end{abstract}

Como se nota, os portugueses que iniciaram o processo de colonização do Brasil eram originários de várias regiões e classes sociais de Portugal. Mais tarde, juntando-se a eles, vieram os negros escravizados de diversas regiões da África, falantes principalmente das línguas do grupo banto (umbundo, quimbundo e quicongo). A partir disso, recorre-se a Antunes (2015), autora que entende que a identidade não se desvincula da tríade língua, cultura e povo, pois a sua formação está intimamente ligada à manifestação cultural coletiva, expressando-se na mediação das linguagens, principalmente a verbal. Essas quatro vertentes estão interconectadas dentro de um sistema de valores e paradigmas da sociedade e não podem ser abordadas isoladamente, por isso Aragão (2010/2011) relata a necessidade de que os estudos de língua ocorram em consideração ao contexto sociocultural onde o discurso é produzido, sendo isso imprescindível para se conhecer a relação entre língua, sociedade e

\footnotetext{
12 Ainda que não se paute na linha teórica da Análise do Discurso (AD), a citação de Brandão (2012) se justifica pela exatidão com que representa o ponto de vista a partir do qual se desenvolve este artigo. Como, em pesquisas deste tipo, não se deve alijar o componente linguístico, invocar um pressuposto de língua na AD não desvia a linha teórica aqui adotada.
} 
cultura, pois são esses fatores que abarcam os aportes linguísticos das línguas africanas no português brasileiro, assim como as suas variações.

\begin{abstract}
As vozes dos quatro milhões de negro-africanos que foram trasladados para o Brasil ao longo de mais de três séculos consecutivos [...] participaram da configuração do português brasileiro não somente com palavras que foram ditas a esmo e 'aceitas como empréstimos pelo português', na concepção vigente, mas também nas diferenças que afastaram o português do Brasil do de Portugal (PESSOA DE CASTRO, 2011, p. 01).
\end{abstract}

A partir da citação, entende-se que as vozes dos negros, por meio de sotaques, sintaxe, dupla negação ("Não vou não") e centenas de palavras que enriqueceram a língua portuguesa, ajudaram a compor a riqueza linguística da superveniente língua brasileira, também marcada por itens lexicais compartilhados por toda a sociedade, uma vez que a maioria dos quatro milhões de africanos escravizados trazidos para o Brasil foi espalhada por todas as regiões, desde o início da comercialização desses, no século XVI, até o final, no século XIX.

Assim, o século XIX foi o período que mais se importou africanos escravizados, além de ser o mais recente em relação aos tempos atuais, sendo razoável supor que estes africanos, majoritários referentes a toda a população escrava de Campos, de todos os tempos, são os que mais influenciaram na língua campista atual, tendo um papel preponderante na formação da identidade do município, pois fomentou os valores, as ideologias, as crenças e as concepções de tal povo, sendo a herança fonética africana uma expressão identitária. Essa herança ajuda a evidenciar uma peculiaridade do linguajar do povo campista, já que a maioria dos africanos escravizados que vieram para a planície no período colonial e imperial manejava as línguas do grupo banto.

Ocorreu um contato forçado e prolongado com a língua portuguesa; primeiramente com aquela utilizada pelos 'pombeiros', recrutadores de cativos no interior das terras; a seguir, ao longo da costa africana, com os 'negreiros', brasileiros, que seriam talvez seus futuros senhores. Para muitos escravos originários de Angola, o multilinguismo encontrado no Brasil, resultante do convívio de línguas africanas e português, não será inédito, o que poderá explicar tanto o emprego de uma língua veicular africana quanto o uso do português falado pelos senhores (PETTER, 2005, p. 201). 
Complementando as informações contidas na citação acima, registra-se que Pessoa de Castro (2011) relata que a maioria dos falantes africanos comercializados para o Brasil não entendia com clareza a língua portuguesa e, por isso, idealizou outra forma de comunicação que resultou na africanização do português brasileiro, isso porque os africanos transferiram de forma natural para a nova língua hábitos articulatórios ${ }^{13}$ de sua língua materna. Além disso, a autora comenta que existem semelhanças estruturantes que aproximam as línguas negroafricanas do grupo banto com o português arcaico ${ }^{14}$.

Esse tipo de aproximação casual, mas notável, provavelmente possibilitou a continuidade do tipo prosódico de base vocálica do português antigo na modalidade brasileira, afastando-a, portanto, do português de Portugal, de pronúncia muito consonantal. (Cf. a pronúncia brasileira *pi.neu, *a.di.vo.ga.do, *ri.ti.mo em lugar de pneu, ad.vo.ga.do, rít.mo) (PESSOA DE CASTRO, 1984, p. 8).

Nesse sentido, a diáspora africana para o Brasil representa um dado considerável nas mudanças linguísticas ocorridas no português lusitano. Petter (2005, p. 203) menciona o surgimento da língua veicular africana que referencia "a economia de comunicação, pela necessidade de ultrapassar o esfacelamento desses diversos falares muito próximos tipologicamente da língua africana utilizada nas minas, no século XVIII”. Esse é um dos fatores que, possivelmente, desencadearam o fenômeno do rotacismo, muito característico na linguagem popular do brasileiro. Compreendido como um fenômeno fonético-fonológico, o rotacismo é responsável pela alternância estrutural linguística de fonemas (a alternância entre os fonemas /1/ e /r/). Cristófaro- Silva (2015) define rotacismo como fenômeno fonológico pertinente à efetivação fonética de um som rótico em que substitui um som lateral, ou viceversa. Segundo a autora "no português, o rotacismo ocorre, por exemplo, quando a substituição da líquida lateral [1] pela vibrante simples ou tepe, [r]. Por exemplo, em casos de rotacismo a palavra blusa é pronunciada como [bruza].”. (CRISTÓFARO-SILVA, 2015, p. 197)

\footnotetext{
13 Os sons vocais são produzidos de acordo com os movimentos e posições articulatórios da língua; e pelos aspectos físicos envolvidos nessa produção. Tal produção pode variar de uma língua para outra, por exemplo: os africanos escravizados trouxeram para o Brasil costumes e tradições culturais, como as pronúncias, que contrastam com a maioria dos sons produzidos na língua portuguesa.

${ }^{14}$ Quanto a essas semelhanças estruturais, Pessoa de Castro (2011) menciona o sistema das sete vogais orais (a, é, e, i, ó, ô, u) e a estrutura silábica (CV.CV.) em que toda consoante é seguida de uma vogal (Ex.: falá por falar; Brasiu por Brasil, etc.).
} 
Pessoa de Castro (1978) assevera que o linguajar rural é resultante da interação mútua entre as línguas africana e portuguesa, com tendência maior para o alcance dos padrões do português colonial brasileiro. Devido a isso, é possível que o indivíduo da baixada campista colonialista, por ter se acostumado ao convívio campestre, sem conhecimento de outras formas de vida, sobretudo pelas precárias comunicações da época, pouco tenha acompanhado $^{15}$ a evolução da língua portuguesa falada no Brasil.

Dessa forma, há, indubitavelmente, vocábulos do português medieval que foram mantidos em Campos dos Goytacazes devido também ao isolamento geográfico, isso ocorreu na Planície Goytacá. Consiste no fenômeno de 'congelamento linguístico' de termos do Português arcaico na citada região (SILVA e SILVA, 2016, p. 48).

Sobre essa questão, Lamego Filho (1945) diz que o mundo do colono dos distritos da baixada ficou estagnado, desde a colonização até início do século $\mathrm{XX}$, resumindo-se ao convívio familiar e comunitário na fazenda, nos serviços campestres e nos canaviais. "Uma vez por outra é que ele [o indivíduo] se desloca para a Vila" (LAMEGO FILHO, 1945, 129). Esse isolamento enraizou o indivíduo no campo dificultando o acesso às comunicações.

Até então isolado do mundo pelas comunicações precárias, não conhecera outra vida. Os próprios imigrantes são da mesma classe. O tempo do senhor do engenho, do grande sobrado civilizador, ainda não chegou. Estamos na época da engenhoca e do casebre de sopapo (LAMEGO FILHO, 1945, p. 153).

Este trecho é endossado por Faria (1997), que aponta uma característica específica de Campos, na qual predominavam pequenas e médias propriedades, com poucos escravos. Nessas propriedades, era pouca a diferenciação cotidiana entre senhores e escravos, que muitas vezes trabalhavam lado a lado na lavoura. Para isso, a autora usa os seguintes dados:

"Na Capitania da Paraíba do Sul, em 1785, das 1201 unidades produtivas existentes, expressivos $73 \%$ eram escravistas, obviamente sendo os donos de engenhos de cana os que mais concentravam essa mão-de-obra, já que esmagadores $98 \%$ deles eram escravistas. Mas, seguindo a regra a média de escravos era muito baixa, mesmo

\footnotetext{
15 Aqui o termo é utilizado com o sentido de "ter contato".
} 
sendo uma região produtora de açúcar: 35 para donos de engenhos, 6 para lavradores de cana, 5 para lavradores de mandioca e 7 para pecuaristas” (FARIA, 1997, p. 50).

Outro fator importante mencionado por Lamego Filho (1945) sobre o isolamento da zona rural campista diz respeito à ausência do ensino regular na região. Somente com a Proclamação da República do Brasil é que o poder municipal campista democratizou a educação no meio rural e, mesmo assim, mantendo os menos favorecidos distantes. Por esse motivo, os descendentes dos primeiros colonos reproduziram a instrução linguística inicial que influenciou a linguagem popular da região, juntamente com o linguajar afro-negro ${ }^{16}$ conservado pelo padrão linguístico da colonização do município. A integração entre os territórios campistas ocorreu com o desenvolvimento da região, intensificando a comunicação entre os distritos e a área central do município.

Sendo o rotacismo é uma variação fonética presente na pronúncia de determinado indivíduo, apresentando-se como um fenômeno de mutação entre as consoantes líquidas alveolares, é importante registrar que Bagno (2013) explica acerca do preconceito linguístico que os falantes podem sofrer quando tal fenômeno ocorre na fala. Para ele, o rotacismo forneceu subsídios para a formação da língua portuguesa padrão, que evoluiu e se transformou no que hoje se chama de português arcaico e, por isso mesmo, os falantes que “cometem" tal fenômeno são vistos como ignorantes. Eis o Quadro 1:

\begin{tabular}{|l|l|l|}
\hline PORTUGUES PADRÃO & ETIMOLOGIA & ORIGEM \\
\hline branco & $>$ blank & Germânico \\
\hline Brando & $>$ blandu & Latim \\
\hline cravo & $>$ clavu & Latim \\
\hline dobro & $>$ duplu & Latim \\
\hline Escravo & $>$ sclavu & Latim \\
\hline fraco & $>$ flaccu & Latim \\
\hline
\end{tabular}

16 Termo utilizado pelo historiador Jacques Raimundo no livro O elemento afro-negro na língua portuguesa. 


\begin{tabular}{|l|l|l|}
\hline Obrigar & $>$ obligare & Latim \\
\hline
\end{tabular}

Quadro 1: Demonstração etimológica da ocorrência do rotacismo

Fonte: Bagno (2013)

Conforme se pode verificar no Quadro 1, palavras que, etimologicamente, eram grafadas com /1/, na passagem para o português padrão, sofreram rotacismo, ainda que esses vocábulos tenham origens diversas. É relevante registrar, pois, que o rotacismo é historicamente explicável e que o fenômeno pode ter causas distintas. Considerando que o rotacismo não se trata de uma descrição de "atraso mental" dos falantes "incapazes" de pronunciar o português, e sim de um fenômeno fonético que proveu a formação da própria língua portuguesa padrão (BAGNO, 2013), é preciso notar que "ele continua vivo e atuante no português não-padrão, como em broco, chicrete, pranta, Cráudia, porque essa variedade não-padrão deixa que as tendências normais e inerentes à língua se manifestem livremente" (BAGNO, 2013, p. 42). Apesar de o autor não mencionar o fenômeno como herança africana, as obras de Aragão (2010/2011) e Pessoa de Castro (2011) assim o apontam.

\footnotetext{
Muitos dos fatos fonético-fonológicos determinantes das variantes regionais e/ou sociais do Português do Brasil são atribuídos à influência do africano, embora alguns estudiosos coloquem dúvidas quanto a essa origem, preferindo creditá-los à evolução ou ao conservadorismo da própria língua portuguesa (ARAGÃO, 2010/2011, p. 8).
}

Com base em autores como Aragão (2010/2011) e Pessoa de Castro (2011), por exemplo, é que se entende que o rotacismo, como elemento da fonética africana, pode incidir sobre o linguajar do povo campista, marcando a formação da sua identidade, especialmente se considerarmos o universo ruralista e a população predominantemente africana, o que perdurou por mais de três séculos. Como se vê, a questão linguística perpassa o aspecto social.

\section{Considerações finais}

A questão identitária do povo campista tem raízes históricas e, conforme alegado pelos Parâmetros Curriculares Nacionais para o Ensino Médio (BRASIL, 2000, p. 5), a "linguagem é herança social", tornando-se um importante instrumento de difusão cultural das diversidades 
étnicas trazidas pelos habitantes que povoaram estas terras, por meio da interação e da comunicação entre os falantes dentro de um mesmo espaço social.

Dessa forma, o conhecimento da história da sociedade campista é primordial para que haja a valorização da cultura africana no município. Nesse sentido, as escolas campistas precisam encontrar estratégias de ação que incentivem a curiosidade dos alunos no que tange ao conhecimento da identidade da população nativa em Campos dos Goytacazes, o que abrange a questão linguística. Não se tem a pretensão de esgotar o assunto com este trabalho, até porque, na pesquisa bibliográfica para a elaboração deste artigo, houve dificuldades em encontrar obras que discutissem o tema específico do rotacismo em Campos. Então, tem-se aqui um material de reflexão inicial para que os interessados no assunto possam ponderar acerca da relação entre a realização fonética do rotacismo e o contexto histórico-social de Campos dos Goytacazes, podendo, futuramente, desenvolver outros trabalhos que discutam o referido fenômeno nesta cidade.

A presença negra no processo de construção da identidade de Campos dos Goytacazes foi demonstrada, ressaltando-se o rotacismo como possível herança fonético-fonológica africana presente no falar dos nativos de tal região, o que foi possível por meio da constatação geral de Aragão (2010/2011). O entendimento do processo de colonização e a influência histórica dos negros escravizados nestas terras são, pois, elementos que colaboram para cumprir, em parte, disposições expressas nas Diretrizes Curriculares Nacionais para a Educação das Relações Étnico-Raciais e para o Ensino de História e Cultura Afro-Brasileira e Africana, já que é de capital importância compreender que o hibridismo de povos em Campos, vislumbrado a partir da óptica da relação escravista, é característica da formação sociocultural de tal município. Além do mais, a língua e a identidade, abordadas por meio da questão do rotacismo, apontam para um fator, dentre vários, da configuração linguística dos campistas.

Por fim, o rotacismo, considerado como uma herança africana, possivelmente é resultado da presença maciça dos povos de África, que "pulverizaram” cultura, língua e identidade no município de Campos dos Goytacazes, e essa tradição fonética secular talvez carregue preconceito justamente por causa da posição do negro na relação escravista com seu senhor. 


\section{Referências}

ANTUNES, Irandé. A língua e a identidade cultural de um povo. In: ANDRÉ, Valente (org.). Língua portuguesa e identidade: marcas culturais. Rio de Janeiro: Caetés, 2015.

ARAGÃO, Maria do Socorro Silva de. Africanismos no português do Brasil. Revista de Letras, vol. 30, 1/4, jan. 2010/dez. 2011, p. 7-16. Disponível em: http://www.revistadeletras.ufc.br/Revista\%20de\%20Letras\%20Vol.30\%20-

$\% 201.4 \% 20 \% 20$ jan.\%202012\%20.\%20dez.\%202011/r130art01_Africanismos_no_portugues_ do_Brasil.pdf. Acesso em: 28 fev. 2018.

BAGNO, Marcos. A língua de Eulália: novela sociolingüística. São Paulo: Contexto, 1997.

Gramática de bolso do português brasileiro. São Paulo: Parábola Editorial, 2013.

BECHARA, Evanildo. Moderna gramática portuguesa - conforme o novo acordo ortográfico. 37. ed. rev. ampl. e atual. Rio de Janeiro: Nova Fronteira, 2009.

BRANDÃO, Helena Hathsue Nagamine. Introdução à análise do discurso. 3. ed revisada. Campinas, SP: Editora da Unicamp, 2012.

BRASIL.. Lei 12.288 de 20 de julho de 2010. Estatuto da Igualdade Racial Disponível em: http://www.planalto.gov.br/ccivil_03/_ato2007-2010/2010/lei/112288.htm. Acesso em: 09 fev. 2018.

Ministério da Educação/Secad. Diretrizes curriculares nacionais para a educação das relações étnico-raciais e para o ensino de história e cultura afro-brasileira e africana na educação básica. 2004. Disponível em: http://www.acaoeducativa.org.br/fdh/wpcontent/uploads/DCN-sEducacao-das-Relacoes-Etnico-Raciais.pdf. Acesso em: 05 mai. 2017.

Lei de Diretrizes e Bases da Educação Nacional. Lei n. 9394, de 20 de dezembro de 1996. Disponível em: http://www.planalto.gov.br/ccivil_03/Leis/L9394.htm. Acesso em: 05 mai. 2017.

$$
\text { Lei 10.639, de } 09 \text { de janeiro de } 2003 .
$$

Altera a Lei $n^{\circ} 9.394$, de 20 de dezembro de 1996, que estabelece as diretrizes e bases da educação nacional, para incluir no currículo oficial da Rede de Ensino a obrigatoriedade da temática "História e Cultura Afro-Brasileira", e dá outras providências. Disponível em: http://www.planalto.gov.br/ccivil_03/leis/2003/L10.639.htm. Acesso em: 28 fev. 2018.

. Ministério de Planejamento, Orçamento e Gestão. Instituto Brasileiro de Geografia e Estatística - Censo Demográfico 2010. Disponível em: http://www.censo2010.ibge.gov.br/sinopse/index.php?uf=33\&dados=1. Acesso em: 05 mai. 2017.

\footnotetext{
Ministério de Planejamento, Orçamento e Gestão. Instituto Brasileiro de Geografia

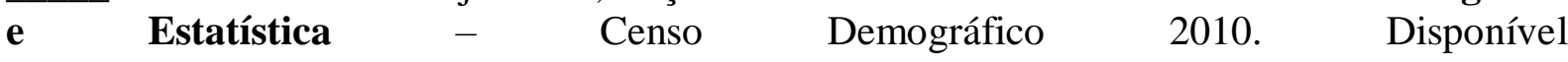
em:https://cidades.ibge.gov.br/v4/brasil/rj/camposdosgoytacazes/pesquisa/23/25888?detalhes $=$ true $\&$ localidade $1=330455$ Acesso em: 05 mai. 2017.
} 
Secretaria de Educação Média e Tecnológica. Parâmetros Curriculares Nacionais: Parte II. Linguagens, Código e suas Tecnologias. Brasília: MEC, 2000. Disponível em: http://portal.mec.gov.br/seb/arquivos/pdf/14_24.pdf. Acesso em: 07 jan. 2015.

CIDAC - Centro de Informações de Dados de Campos. Disponível em: http://cidac.campos.rj.gov.br/wp-content/uploads/files/perfil-bairros-2014. Acesso em: 05 mai. 2017.

CRISTÓFARO-SILVA, Thaïs. Fonética e fonologia do português: roteiro de estudos e guia de exercícios. 10. ed. São Paulo: Contexto, 2015.

CUNHA, Ana Stela; PETTER, Margarida. Línguas africanas no Brasil. In: PETTER, Margarida (org.). Introdução à Linguística Africana. São Paulo: Contexto, 2015.

FARIA, Sheila Siqueira de Castro. A colônia brasileira: economia e diversidade. São Paulo: Moderna, 1997.

LAMEGO FILHO, Alberto. O Homem e o Brejo. Rio de Janeiro: Instituto Brasileiro de Geografia e Estatística - Conselho Nacional de Geografia, 1945.

LARA, Silva Hunold. Campos da violência: escravos e senhores na Capitania do Rio de Janeiro, 1750-1808. Rio de Janeiro: Paz e Terra, 1988.

LIMA, Lana Lage da Gama. Rebeldia negra e abolição. Rio de Janeiro: Achiamé, 1981.

LUCCHESI, Dante. A diferenciação da língua portuguesa no Brasil e o contato entre línguas. Estudos de Lingüística Galega, Santiago de Compostela, n. 4, julho de 2012, p. 45-65. Disponível em: http://www.usc.es/revistas/index.php/elg/article/view/403/400. Acesso em: 16 fev. 2017.

LUCCHESI, Dante et al. O português afro-brasileiro: as comunidades analisadas. In: LUCCHESI, Dante. BAXTER, Alan; RIBEIRO, Ilza (orgs.). O português afro-brasileiro. Salvador: EDUFBA, 2009. Disponível em: http://books.scielo.org. Acesso em: 15 fev. 2017.

MENDONÇA, Renato. A influência africana no português do Brasil. 2. ed. Brasília: FUNAG: 2012.

OSCAR, João. Escravidão e Engenhos. Rio de Janeiro: Achiamé, 1985.

PEIXOTO, Dídimo de Castro. História Fluminense: subsídios à cadeira de estudos sociais. 3. ed. amp. 1969.

PESSOA DE CASTRO, Yeda. A influência das línguas africanas no português brasileiro, 1984. 
Marcas de Africania no português brasileiro. Africanias, 2011. Disponível em: http://www.africaniasc.uneb.br/pdfs/n_1_2011/ac_01_castro.pdf. Acesso em: 20 de dez. 2017.

Os falares africanos na interação social do Brasil colônia. Bahia: UFBA - Centro de Estudos baiano, 1978.

PETTER, Margarida. Línguas africanas no Brasil. Gragotá, Niterói/RJ, n. 19, 2005, p. 193217. Disponível em: http://www.gragoata.uff.br/index. php/gragoata/article/view/351. Acesso em: 08 mar. 2018.

PINTO, Jorge Renato Pereira. Um pedaço da terra chamada Campos. 2. ed. Fundação Jornalista Osvaldo Lima. Campos dos Goytacazes, RJ. 2006.

RAIMUNDO, Jacques. O elemento afro-negro na língua portuguesa. Rio de Janeiro: Renascença, 1933.

SILVA, Moisés Pereira; SILVA, Valéria de Aguiar Lima. O português medieval e o atual: congelamento linguístico na Baixada Campista. Perspectivas online: humanas \& sociais aplicadas; Campos dos Goytacazes, 17 (6), 41-72, 2016. Disponível em: http://www.seer.perspectivasonline.com.br/index.php/humanas_sociais_e_aplicadas/article/vi ew917. Acesso em: 15 jan. 2018.

SOARES, Márcio de Souza. Presença africana e arranjos matrimoniais entre os escravos. História: Questões \& Debates, Curitiba, n. 52, p. 75-90, jan./jun. 2010. Disponível em: revistas.ufpr.br/historia/article/download/24110/16136. Acesso em: 28 fev. 2018.

Recebido em 04 de setembro de 2018. Aceito em 30 de dezembro de 2018. 